\title{
BMJ Open Prevalence and temporal pattern of hospital readmissions for patients with type I and type II diabetes
}

\author{
Xiaoqian Liu, ${ }^{1}$ Yuanyuan Liu, ${ }^{1}$ Yuanjun Lv, ${ }^{2}$ Changping Li, ${ }^{1}$ Zhuang Cui, ${ }^{1}$ Jun Ma ${ }^{1}$
}

To cite: Liu X, Liu Y, Lv Y, et al. Prevalence and temporal pattern of hospital readmissions for patients with type I and type II diabetes. BMJ Open 2015;5: e007362. doi:10.1136/ bmjopen-2014-007362

- Prepublication history and additional material is available. To view please visit the journal (http://dx.doi.org/ 10.1136/bmjopen-2014007362).

$\mathrm{XL}, \mathrm{YLi}$ and YLv contributed equally.

Received 4 December 2014 Revised 14 April 2015 Accepted 12 May 2015

\section{CrossMark}

${ }^{1}$ College of Public Health, Tianjin Medical University, Tianjin, China

${ }^{2}$ Division of General Internal Medicine, Tianjin Hospital, Tianjin, China

Correspondence to

Dr Jun Ma;

junma@tijmu.edu.cn

\section{ABSTRACT}

Objective: Repeated hospitalisation for patients is common and costly, yet partly preventable. However, we know little about readmissions for patients with diabetes in China. The current study aims to assess the frequency and temporal pattern of and risk factors for all-cause readmission among hospitalised patients with diabetes in Tianjin, China.

Method: This retrospective, cohort analysis used the Tianjin Basic Medical Insurance Register System data of 2011. The patterns of and the reasons for all-cause readmissions for patients with diabetes were described. The differences of readmission-free survival (RFS) between newly and previously diagnosed patients were compared. Time-dependent Cox models were established to identify the risk factors for readmission at different time intervals after discharge.

Results: Readmission rates were approximately $30 \%$, with the most common diagnoses of cerebral infarction (for type I) or diabetes (for type II) for patients with diabetes. The majority of patients were readmitted to the hospital after more than 90 days, followed by $8-30$ days (all $p=0.002$ ). Approximately $37.2 \%$ and $42.8 \%$ of readmitted patients with type I and type II diabetes were diagnosed previously, and the RFS rates for previously diagnosed patients were significantly lower than for newly diagnosed patients at any time interval after discharge. Prior history of diabetes (all $p<0.05$ ), length of stay (all $p<0.01$ ) and reimbursement ratio $(90 \%$ vs $>92 \%$, all $p<0.0002)$ were consistently associated with the RFS for patients readmitted to the hospital at $<7,8-30,31-60$ and $61-90$ days.

Conclusions: Hospital readmissions among patients with diabetes were affected by the diagnosis status. Patient characteristics and the quality of healthcare might regulate short-interval and long-interval hospital readmission, respectively, after discharge.

\section{INTRODUCTION}

Currently, China has the largest population with diabetes among the developing nations. ${ }^{1}$ The prevalence ranges from $8.3 \%$ to $12.7 \%$ with geographical variation, and one-third of patients are living with previously undiagnosed diabetes. ${ }^{2}$ In China, the direct medical cost of diabetes-related

\section{Strengths and limitations of this study}

- This is, to the best of our knowledge, the first study to discover the prevalence and temporal pattern of and the factors for readmission for patients with type I and type II diabetes in China.

- We used the time-dependent Cox proportional hazards model to assess the impact factors for readmissions, taking into account the fact that the response variable changes over time.

- We found that patients who were discharged with previously diagnosed diabetes consistently have lower readmission-free survival and that short-interval and long-interval readmission after discharge might be driven by different factors.

- Some extra elements, such as socioeconomic status of patients and more detailed information of their disease conditions, may contribute to readmissions, but these data were unavailable in the current study.

- This study used administrative data, which are not always adequate and accurate for patient information. As a consequence, we could not distinguish type I and type II diabetes perfectly and could not assess readmission in the areas of transition of care and outpatient care.

disorders was estimated at US\$26.0 billion in 2007, and costs are expected to increase to $\$ 47.2$ billion by $2030,{ }^{3}$ much of which is due to the usage of in-hospital services. ${ }^{4-7}$ Inpatient management of patients with diabetes is often less than optimal, and suboptimal management is associated with excess mortality, increased length of stay and increased odds of readmission for discharged patients. $^{8-10}$ Diabetes has been previously cited as one of the diseases for which readmissions are likely to be a valid measure of the quality of care in developed countries. ${ }^{8}$ Putting the necessity of awareness aside, readmissions for patients with diabetes are preventable, ${ }^{11}$ especially for older patients, if these patients comply with effective drug treatment, receive adequate post-discharge care and control the progression of the basic 
disease. ${ }^{12}$ These steps can only be realised though the cooperation of patients, hospitals and public health as a whole. $^{13}$ Therefore, reducing readmission should become a policy focus because it represents an opportunity to improve quality and reduce healthcare costs simultaneously, yet little is known about the profile of readmission for patients with diabetes in China.

Beyond simply describing the current situation, there is an increasing urgency to determine the influencing factors. Previous studies indicated that readmission is primarily driven by the use of health resources of communities where hospitals are located, ${ }^{14}$ hospitals' performance, ${ }^{15}$ coexisting conditions of a patient ${ }^{14} 15$ and different types of medical insurance. ${ }^{16}$ Notably, another possibility is diagnosis status, namely 'newly' or 'previously' diagnosed. Studies have proven that the longer the duration of diabetes, the worse the prognosis of the patient, ${ }^{9}$ because a history of diabetes is associated with high risk of morbidity and mortality for related disorders. ${ }^{17-20}$ However, we are unaware of prior work on the hazards of readmission for patients with diabetes.

The city of Tianjin is located in the eastern coastal area of China, where the prevalence of diabetes is the highest. It is the third largest city, and its political status is equal to that of the provinces. In this region, the positive rate of high blood sugar screening has been assessed to be $12 \%,{ }^{2}$ which approaches the peak of diabetes prevalence in China. Hence, in this area, the opportunity for evaluating the profile of readmission for patients with diabetes is unique. In understanding the prevalence of and risks for readmission, and recognising who is more vulnerable, publicly reported conditions can help improve the design of interventions that target the proper subjects and healthcare facilities. In this study, we report the prevalence of readmission for patients with diabetes in Tianjin, China, discover the frequent medical reasons for readmission and determine whether readmission is associated with diagnosis status. By establishing the Time-to-Event proportional risk model, we estimated the HR for patients with either type I or type II diabetes readmitted to the hospital within a year and within 7, 8-30, 31-60, 61-90 and >90 days between the index discharge and the next hospitalisation. We aimed to provide insights into the possible impact factors of readmission and shed light on the areas where interventions can lead to better medical services and lower costs.

\section{MATERIALS AND METHODS}

Data and studied population

We created a retrospective cohort using the Tianjin Basic Medical Insurance Register System (TBMIRS) database to identify all records of hospitalisations with discharge diagnoses of diabetes between 1 January 2011 and 30 December 2011 in Tianjin, China, for Basic Medical Insurance (BMI) beneficiaries (International Classification of Diseases, Tenth Revision, Clinical Modification (ICD-10) codes for diabetes, E10-E14).
Since 2009, the coverage rate of BMI has been $>90 \%$; thus, TBMIRS can identify almost all residents in Tianjin. ${ }^{21}$ We used a randomised stratified sampling method, selecting $50 \%$ of these records as a sample. We were able to ascertain each patient's exclusive personal code, age, sex and clinical diagnoses, and to gather information on the characteristics of hospitals where the patient was admitted. We excluded patients who were transferred to other hospitals on the day of discharge and patients who were discharged on the day of admission. Only patients surviving to discharge were included. Our final sample consisted of 62746 discharges of 37620 patients; among them, 16548 were discharged with type I diabetes and 21072 were discharged with type II diabetes. All patient records and information were anonymised and de-identified prior to analysis.

\section{Assessment of hospital readmission and definitions of variables}

We defined patients with multiple hospitalisation records as readmission patients; other patients were defined as readmission-free patients. The rates of readmission were defined as: the number of patients discharged from any recorded hospital and readmitted with any medical reason to any recorded hospital within $7,8-30,31-60,61-90$ or $>90$ days, divided by the total number of patients who were discharged alive from recorded hospitals. To identify the most vulnerable patients for readmission, patients were categorised as those with either previously or newly diagnosed diabetes. Previously diagnosed patients were those with a prior history of diabetes and were defined as those who had any previous usage of diabetes-related medical services (in pharmacies, as outpatients or in hospitals) in the 1 -year period before the index hospitalisation. Patients who had no diabetes-related claims in the 1-year period before the index hospitalisation were categorised as newly diagnosed with diabetes.

To examine the primary reasons for readmission at discharge, we identified the top five most frequent diagnoses based on ICD-10 and tabulated them for readmission by year and by five time intervals after discharge for each type of diabetes. We also tabulated patient demographic characteristics, including age, sex and employment status (employed or retired); patient clinical characteristics, including presence or absence of diabetes-related complications and other comorbidities, such as primary hypertension $(\mathrm{PH})$, congestive heart failure (CHF) and infectious diseases (IDs, including hepatitis, sexually transmitted diseases, tuberculosis, typhoid and dysentery), with or without an operation during the index hospitalisation, and the length of stay; and the reimbursement ratio of healthcare costs, which represents the portion of hospitalisation costs for which the patient will be reimbursed and is tailored for patients each time they visit a healthcare facility. We also analysed the hospital-based characteristics, which present a dividing line to distinguish hospital quality 
levels in China. According to the Ministry of Public Health of China, the hospitals (or clinics) that only provide primary healthcare services to a specific local community and contain $<100$ beds are defined as primary hospitals. Secondary hospitals provide primary healthcare services to more than one local community, serve as teaching and research hospitals, and are equipped with no $<101$ beds. Tertiary hospitals are equipped with more than 501 beds, can provide highly professionalised health services without regional boundary limitations, have the ability to train advanced professionals and conduct scientific research independently. Finally, the median direct medical costs of index hospitalisation were reported between groups.

\section{Statistical analysis}

We first used $\chi^{2}$ test, Fisher's exact test or Wilcoxon test to compare the characteristics of patients and hospitals between readmission and readmission-free groups for each type of diabetes. The comparison of readmission rates at different time intervals between newly and previously diagnosed patients with diabetes was performed by $\chi^{2}$ test for each type of diabetes. Log-rank test were used to compare the different survival rates between patients with newly and previously diagnosed diabetes.

We used the time-dependent Cox proportional hazards model to assess the impact of a previous diagnosis of diabetes on 1-year readmissions and readmissions within 7, 8-30, 31-60 and 61-90 days. The proportional hazards model is usually expressed in terms of a single survival time value for each person, with possible censoring. Andersen and Gill reformulated the same problem as a counting process. ${ }^{22}$ The data for a subject are presented as multiple 'observations', each of which applies to an interval of observation (start, stop). The day of discharge for an index hospitalisation was the start time, and the day of readmission after discharge was the stop time. Data were censored at the end of the observation period (eg, 7, 30 or 60 days). Covariates were the patients' and hospitals' characteristics, including age, sex, employment status, type of diabetes, length of stay, presence or absence of diabetes-related complications (diabetic ketoacidosis, non-ketotic hyperosmolar coma, diabetic cardiomyopathy, diabetic nephropathy, diabetic neuropathy, diabetic retinopathy, diabetic myonecrosis and diabetic foot), HP, CHF and ID, with or without any operation during the index hospitalisation, hospital grade where the patient was admitted at the index hospitalisation and the reimbursement ratio of healthcare costs for each subject.

All reported $\mathrm{p}$ values are two sided. All analyses were conducted with R software (V.3.3.1.).

\section{Validity and sensitivity analysis}

To assess the stability of the built model at the baseline scenario, we performed a sensitivity analysis based on a computer-intensive resampling bootstrap method. The mean of coefficients $\left(\widehat{\theta}_{1}\right)$ for variables was estimated from 1000 testing models, and these models were established using the data of 1000 times repeated sampling with replacement of the baseline records. The baseline model is considered as a stable model if the estimated mean coefficients quantifiably approximated the coefficients in the baseline model. And the variances between the values were acceptable: for each estimated coefficient, $\left(\left|\widehat{\theta}_{\mathrm{i}}-\widehat{\beta}_{\mathrm{i}}\right| / \widehat{\mathrm{S}_{\theta \mathrm{i}}}\right) \times 100 \%$ is smaller than $25 \% .{ }^{23}$ Since there was no standard for distinguishing unplanned readmissions, we performed a sensitivity analysis by repeating our 1-year readmission model but excluded patients with a diagnosis of any type of cancer or with chemotherapy, radiotherapy or biotherapy treatment during the index hospitalisation. As another sensitivity analysis, we evaluated the discrimination of our model. We created Kaplan-Meier (KM) survival curves for predicted risk groups that were separated based on the predicted HRs. These HRs were calculated through the baseline 1-year readmission model. The more widely separated the curves, the better the model discrimination. ${ }^{24}$

\section{RESULTS}

From our final sample, we excluded 1486 patients who were transferred on the day of discharge or discharged on the same day of admission. Of the 37620 patients in our sample, 16548 and 21072 were diagnosed with type I and type II diabetes, respectively, and $29.8 \%$ of the patients with type I diabetes and $29.0 \%$ of the patients with type II diabetes were hospitalised more than once (table 1). For type I diabetes, compared with readmission-free patients, the readmitted patients were older, more often male, retired, and more likely to have $\mathrm{PH}$ and CHF; they also had longer lengths of stay and higher reimbursement ratios, and were more often admitted to lower grade hospitals. Significantly lower median costs for index hospitalisation were found for readmitted patients compared with those for readmission-free patients. These characteristics were similar to those for patients with type II diabetes, except that the readmitted patients were more likely to have diabetes-related complications and ID; no significant difference for gender or operation status was found between groups.

Most patients were readmitted to the hospital at more than 90 days after the index discharges, followed by within 8-30 days. A total of 4925 patients with type I diabetes were readmitted to hospital in 2011, and $37.2 \%$ were diagnosed previously. A total of 6115 patients with type II diabetes were readmitted to hospital in the same year, and $42.8 \%$ were diagnosed previously. Figure 1 shows that, for both types of diabetes, the proportions of readmission for previously diagnosed patients with diabetes were higher than for newly diagnosed patients at 31-60, 61-90 and $>90$ days $(\mathrm{p}=0.002)$.

Table 2 shows the five most frequent medical reasons for readmission. The most frequent primary diagnoses 
Table 1 Discharge characteristics by type of diabetes

\begin{tabular}{|c|c|c|c|c|c|c|}
\hline \multirow[b]{2}{*}{ Variables } & \multicolumn{2}{|c|}{ Patients with type I diabetes $(\mathrm{N}=16548)$} & \multicolumn{2}{|c|}{ Patients with type II diabetes $(\mathrm{N}=21$ 072) } & \multirow[b]{2}{*}{ p Value* } & \multirow[b]{2}{*}{ p Value ${ }^{\star \star}$} \\
\hline & Readmission free & Readmission & Readmission free & Readmission & & \\
\hline Age & $62.3(11.9)$ & $64.2(11.1)$ & $62.7(11.5)$ & $66.0(10.7)$ & $<0.0001$ & $<0.0001$ \\
\hline \multicolumn{7}{|l|}{ Gender } \\
\hline Male & $6532(56.2)$ & $2683(54.5)$ & $8116(54.3)$ & $3251(53.2)$ & 0.043 & 0.151 \\
\hline Female & $5091(43.8)$ & $2242(45.5)$ & $6841(45.7)$ & $2864(46.8)$ & & \\
\hline \multicolumn{7}{|l|}{ Employment status } \\
\hline Yes & $2860(24.6)$ & 897 (18.2) & $3440(23.0)$ & $851(13.9)$ & $<0.0001$ & $<0.0001$ \\
\hline No & $8763(75.4)$ & $4028(81.8)$ & $11517(77.0)$ & $5264(86.1)$ & & \\
\hline \multicolumn{7}{|l|}{ Previously diagnosed diabetes } \\
\hline Yes & $2539(21.8)$ & 1833 (37.2) & 3901 (26.1) & $2615(42.8)$ & $<0.0001$ & $<0.0001$ \\
\hline No & 9084 (78.2) & $3092(62.8)$ & $11056(73.9)$ & $3500(57.2)$ & & \\
\hline \multicolumn{7}{|l|}{ With complications } \\
\hline Yes & $1824(15.7)$ & 807 (16.4) & 3727 (24.9) & $1633(26.7)$ & 0.2753 & 0.007 \\
\hline No & 9799 (84.3) & $4118(83.6)$ & $11230(75.1)$ & $4482(73.3)$ & & \\
\hline \multicolumn{7}{|l|}{ With primary hypertension } \\
\hline Yes & $6901(59.4)$ & 3042 (61.8) & $9488(63.4)$ & $4386(71.7)$ & 0.004 & $<0.0001$ \\
\hline No & $4722(40.6)$ & 1883 (38.2) & 5469 (36.6) & 1729 (28.3) & & \\
\hline \multicolumn{7}{|l|}{ With congestive heart failure } \\
\hline Yes & $333(2.9)$ & 173 (3.5) & $537(3.6)$ & $360(5.9)$ & 0.027 & $<0.0001$ \\
\hline No & $11290(97.1)$ & $4752(96.5)$ & $14420(96.4)$ & $5755(94.1)$ & & \\
\hline \multicolumn{7}{|l|}{ With infectious diseases } \\
\hline Yes & $296(2.5)$ & $133(2.5)$ & $371(2.5)$ & 207 (3.4) & 0.5691 & 0.0003 \\
\hline No & 11327 (97.5) & 4792 (97.2) & $14586(97.5)$ & $5908(96.6)$ & & \\
\hline \multicolumn{7}{|l|}{ With index operation } \\
\hline Yes & $3178(27.3)$ & $1019(20.6)$ & $2020(13.5)$ & $806(13.2)$ & $<0.0001$ & 0.5302 \\
\hline No & 8445 (72.7) & $3906(79.3)$ & $12937(86.5)$ & $5309(86.8)$ & & \\
\hline The length of stays & $12.7(8.3)$ & $13.3(8.4)$ & $12.9(6.5)$ & $13.9(7.3)$ & $<0.0001$ & $<0.0001$ \\
\hline \multicolumn{7}{|l|}{ Reimbursement ratio, \% } \\
\hline$>92$ & $182(1.8)$ & $401(8.2)$ & $312(2.0)$ & $679(11.1)$ & $<0.0001$ & $<0.0001$ \\
\hline 90 & $8581(73.8)$ & $3629(73.7)$ & $11211(75.0)$ & $4586(75.0)$ & & \\
\hline 85 & $2860(24.6)$ & 895 (18.2) & $3434(23.0)$ & 850 (13.9) & & \\
\hline \multicolumn{7}{|l|}{ Hospital grades } \\
\hline First & $969(8.2)$ & 637 (12.9) & $1029(6.9)$ & 872 (14.3) & $<0.0001$ & $<0.0001$ \\
\hline Second & $3333(28.7)$ & 1507 (30.6) & 3881 (25.9) & $1684(27.5)$ & & \\
\hline Third & $7321(63.0)$ & $2781(56.5)$ & $10047(67.2)$ & 3559 (58.2) & & \\
\hline Costs for index hospitalisation & $9350.9(9050.2)$ & $9184.4(9678.4)$ & $8643.7(5998.5)$ & $8589.1(7240.8)$ & $<0.0001$ & 0.0002 \\
\hline
\end{tabular}


Type I diabetes

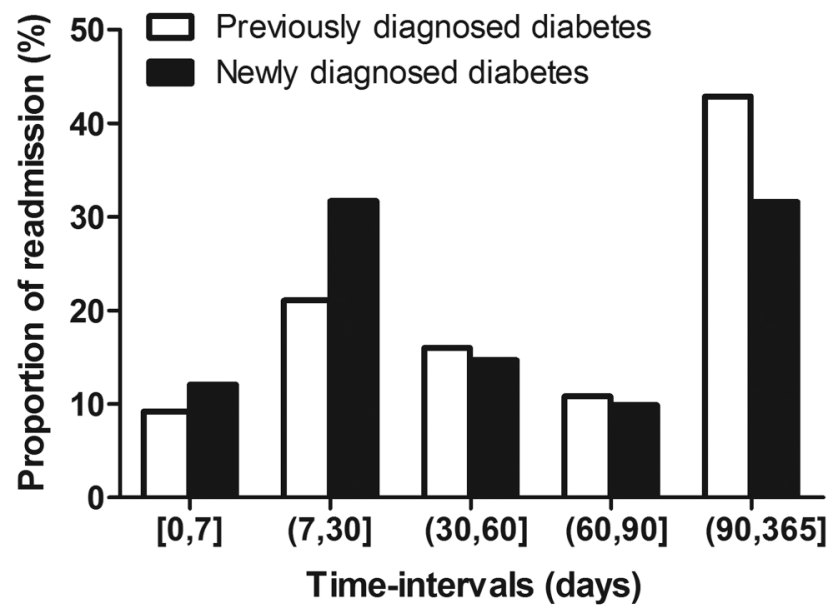

B

Type II diabetes

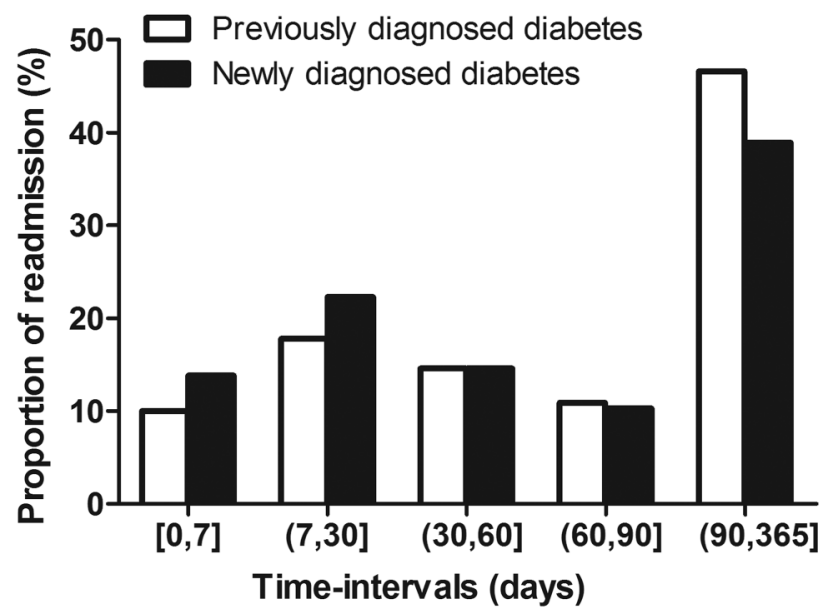

Figure 1 The proportions of readmission for newly and previously diagnosed patients with diabetes showed that, for both type of diabetes, the proportions of readmission for previously diagnosed patients with diabetes were higher than for newly diagnosed patients at intervals of 31-60, 61-90 and $>90$ days $(p=0.002)$.

were cerebral infarction (14\%) and diabetes (16.5\%) for patients with type I and type II diabetes, respectively, which were the same at each time interval. Malignant neoplasm of the breast, bronchus and lung, as well as unspecified heart disease, were also frequent diagnoses for 1-year readmission for patients with type I diabetes. For patients with type II diabetes, the reasons for readmission at each time interval were almost similar to those for 1-year readmission.

We found that the overall 1-year readmission-free survival (RFS) rates of patients with previously diagnosed diabetes were significantly lower than those of newly diagnosed patients (figure 2): 0.67 (0.65-0.68) versus $0.79(0.78-0.79)$ for type I diabetes and 0.70 (0.69-0.72) versus $0.81(0.81-0.82)$ for type II diabetes. This difference was also found for cumulative
RFS rates at all intervals after discharge (table 3, all $\mathrm{p}<0.0001)$.

Multivariate time-dependent Cox proportional hazard regression analyses were used to evaluate the independent impact factors associated with patients' 1-year RFS and RFS at different time intervals after discharge. Online supplementary table S1 shows that a prior history of diabetes was an independent factor associated with 1-year RFS and RFS at any time interval after discharge. The HRs were 1.15 (95\% CI 1.01 to $1.29, \mathrm{p}=0.03$ ), 1.15 (95\% CI 1.05 to $1.25, \mathrm{p}=0.0017$ ), 1.52 (95\% CI 1.37 to $1.68, \mathrm{p}<0.0001)$ and 1.69 (95\% CI 1.50 to 1.90 , $\mathrm{p}<0.0001)$ for patients readmitted to the hospital within 7, 8-30, 31-60 and 61-90 days, respectively, along with HR $1.44(95 \%$ CI 1.38 to $1.50, \mathrm{p}<0.0001)$ for 1 -year readmission. Overall, patients who were older (HR 1.01, $95 \%$ CI 1.00 to $1.01, \mathrm{p}<0.0001$ ), admitted to a primary hospital (HR $0.91,95 \%$ CI 0.85 to $0.97, \mathrm{p}=0.0053$ and HR $0.87,95 \%$ CI 0.81 to 0.93 , $\mathrm{p}<0.0001$ for readmission in secondary and tertiary hospitals, respectively, compared to that in primary hospitals, which had a reference HR of 1), diagnosed with type II diabetes (HR $0.92,95 \%$ CI 0.89 to $0.96, p<0.0001$ for patients with type I diabetes), diagnosed with PH (HR 1.07, 95\% CI 1.03 to $1.12, \mathrm{p}=0.001$ ), CHF (HR 1.16, 95\% CI 1.06 to 1.27, $\mathrm{p}=0.0009$ ), or diagnosed with ID (HR 1.29, 95\% CI 1.16 to $1.44, \mathrm{p}<0.0001$ ) had higher HR for readmission. Patients who experienced longer stays and those who had higher reimbursement ratios of healthcare costs at index hospitalisation consistently had a higher HR of readmission at all time intervals.

Following examination of readmission at each time interval after discharge, the impact factors we found were not consistent. For example, the type of diabetes did not have an impact on 61-90 days of readmission ( $p=0.492)$ and having an operation at index hospitalisation was only associated with a relatively earlier phase of readmission (within 30 days). Notably, the comorbidity of PH had contradictory impacts on RFS; it was a risk factor for 7, 61-90 days and 1-year RFS but a protective factor for RFS within 8-30 days.

The results of the stability evaluation for the baseline model showed that each estimated mean coefficient $\left(\widehat{\theta}_{\mathrm{i}}\right)$ was substantially stable and similar to that estimated from the baseline model. Meanwhile, all $\left(\left|\widehat{\theta}_{\mathrm{i}}-{\widehat{\beta_{i}}}_{\mathrm{i}}\right| \widehat{\mathrm{S}_{\theta \mathrm{i}}}\right) \%$ were smaller than $25 \%$, which means that the baseline 1-year readmission model was highly stable (see online supplementary table S2).

Analyses that excluded patients with a discharge diagnosis of any type of cancer or with a treatment of chemotherapy, radiotherapy or biotherapy did not significantly change our results; the specific HRs were qualitatively similar to those of the baseline 1-year readmission model (see online supplementary table S3). Figure 3 shows the KM-survival curves for RFS as predicted in the baseline model from the HRs. The two curves are well separated, confirming that our model has good discrimination. 
Table 2 Most frequent diagnoses for readmission for patients with diabetes by diagnose status and type of diabetes

\begin{tabular}{|c|c|c|c|c|c|}
\hline $\begin{array}{l}\text { Time intervals after } \\
\text { discharges }\end{array}$ & Most frequent & Second most frequent & Third most frequent & Fourth most frequent & Fifth most frequent \\
\hline \multicolumn{6}{|l|}{ For type I diabetes } \\
\hline $0-7$ days & $\begin{array}{l}\text { Cerebral } \\
\text { infarction (21.4\%) }\end{array}$ & $\begin{array}{l}\text { Chronic ischaemic heart } \\
\text { disease }(5.0 \%)\end{array}$ & $\begin{array}{l}\text { Acute ischaemic heart disease } \\
(3.9 \%)\end{array}$ & $\begin{array}{l}\text { Polyneuropathy in diseases } \\
(3.7 \%)\end{array}$ & $\begin{array}{l}\text { III-defined descriptions of heart } \\
\text { disease }(3.5 \%)\end{array}$ \\
\hline $8-30$ days & $\begin{array}{l}\text { Cerebral } \\
\text { infarction }(8 \%)\end{array}$ & $\begin{array}{l}\text { Malignant neoplasm of } \\
\text { breast }(6.9 \%)\end{array}$ & $\begin{array}{l}\text { Malignant neoplasm of } \\
\text { bronchus and lung }(6.4 \%)\end{array}$ & $\begin{array}{l}\text { Chronic ischaemic heart } \\
\text { disease }(4.2 \%)\end{array}$ & Diabetes $(4.2 \%)$ \\
\hline $31-60$ days & $\begin{array}{l}\text { Cerebral } \\
\text { infarction (10.5\%) }\end{array}$ & Diabetes $(6.9 \%)$ & $\begin{array}{l}\text { Chronic ischaemic heart } \\
\text { disease }(5.5 \%)\end{array}$ & $\begin{array}{l}\text { Acute ischaemic heart } \\
\text { disease }(5.5 \%)\end{array}$ & $\begin{array}{l}\text { Malignant neoplasm of } \\
\text { bronchus and lung }(2.9 \%)\end{array}$ \\
\hline $61-90$ days & $\begin{array}{l}\text { Cerebral } \\
\text { infarction (14.1\%) }\end{array}$ & $\begin{array}{l}\text { Heart disease, } \\
\text { unspecified }(7.0 \%)\end{array}$ & $\begin{array}{l}\text { Chronic ischaemic heart } \\
\text { disease }(6.4 \%)\end{array}$ & $\begin{array}{l}\text { Acute ischaemic heart } \\
\text { disease }(4.6 \%)\end{array}$ & Diabetes $(3.8 \%)$ \\
\hline$>90$ days & $\begin{array}{l}\text { Cerebral } \\
\text { infarction (15.1\%) }\end{array}$ & $\begin{array}{l}\text { Chronic ischemic heart } \\
\text { disease }(7.1 \%)\end{array}$ & $\begin{array}{l}\text { Polyneuropathy in diseases } \\
(5.2 \%)\end{array}$ & $\begin{array}{l}\text { Acute ischaemic heart } \\
\text { disease }(5.2 \%)\end{array}$ & Diabetes (4.5\%) \\
\hline 1 year & $\begin{array}{l}\text { Cerebral } \\
\text { infarction (14\%) }\end{array}$ & $\begin{array}{l}\text { Chronic ischaemic heart } \\
\text { disease }(5.8 \%)\end{array}$ & Diabetes $(4.5 \%)$ & $\begin{array}{l}\text { Acute ischaemic heart } \\
\text { disease }(4.3 \%)\end{array}$ & $\begin{array}{l}\text { Polyneuropathy in diseases } \\
(3.3 \%)\end{array}$ \\
\hline \multicolumn{6}{|l|}{ For type II diabetes } \\
\hline $0-7$ days & Diabetes (17.5\%) & $\begin{array}{l}\text { Cerebral infarction } \\
(16.6 \%)\end{array}$ & $\begin{array}{l}\text { Chronic ischaemic heart } \\
\text { disease }(9.9 \%)\end{array}$ & $\begin{array}{l}\text { III-defined descriptions of } \\
\text { heart disease }(2.9 \%)\end{array}$ & Pneumonia (2.9\%) \\
\hline $7-30$ days & Diabetes (17.3\%) & $\begin{array}{l}\text { Cerebral infarction } \\
(11.3 \%)\end{array}$ & $\begin{array}{l}\text { Chronic ischaemic heart } \\
\text { disease }(9.1 \%)\end{array}$ & $\begin{array}{l}\text { III-defined descriptions of } \\
\text { heart disease }(2.6 \%)\end{array}$ & Pneumonia (2.5\%) \\
\hline $30-60$ days & Diabetes (16.7\%) & $\begin{array}{l}\text { Chronic ischaemic heart } \\
\text { disease }(9.0 \%)\end{array}$ & Cerebral infarction (8.6\%) & $\begin{array}{l}\text { III-defined descriptions of } \\
\text { heart disease }(3.4 \%)\end{array}$ & Pneumonia (2.4\%) \\
\hline $60-90$ days & Diabetes (20.9\%) & $\begin{array}{l}\text { Cerebral infarction } \\
(11.5 \%)\end{array}$ & $\begin{array}{l}\text { Chronic ischaemic heart } \\
\text { disease }(8.5 \%)\end{array}$ & $\begin{array}{l}\text { III-defined descriptions of } \\
\text { heart disease }(3.9 \%)\end{array}$ & Pneumonia (2.9\%) \\
\hline$>90$ days & Diabetes $(29.9 \%)$ & $\begin{array}{l}\text { Cerebral infarction } \\
(11.9 \%)\end{array}$ & $\begin{array}{l}\text { Chronic ischaemic heart } \\
\text { disease }(8.2 \%)\end{array}$ & $\begin{array}{l}\text { Polyneuropathy in diseases } \\
(2.6 \%)\end{array}$ & $\begin{array}{l}\text { III-defined descriptions of heart } \\
\text { disease }(2.6 \%)\end{array}$ \\
\hline 1 year & Diabetes (16.5\%) & $\begin{array}{l}\text { Cerebral infarction } \\
(11.7 \%)\end{array}$ & $\begin{array}{l}\text { Chronic ischaemic heart } \\
\text { disease }(8.7 \%)\end{array}$ & $\begin{array}{l}\text { III-defined descriptions of } \\
\text { heart disease }(2.9 \%)\end{array}$ & Pneumonia $(2.5 \%)$ \\
\hline
\end{tabular}



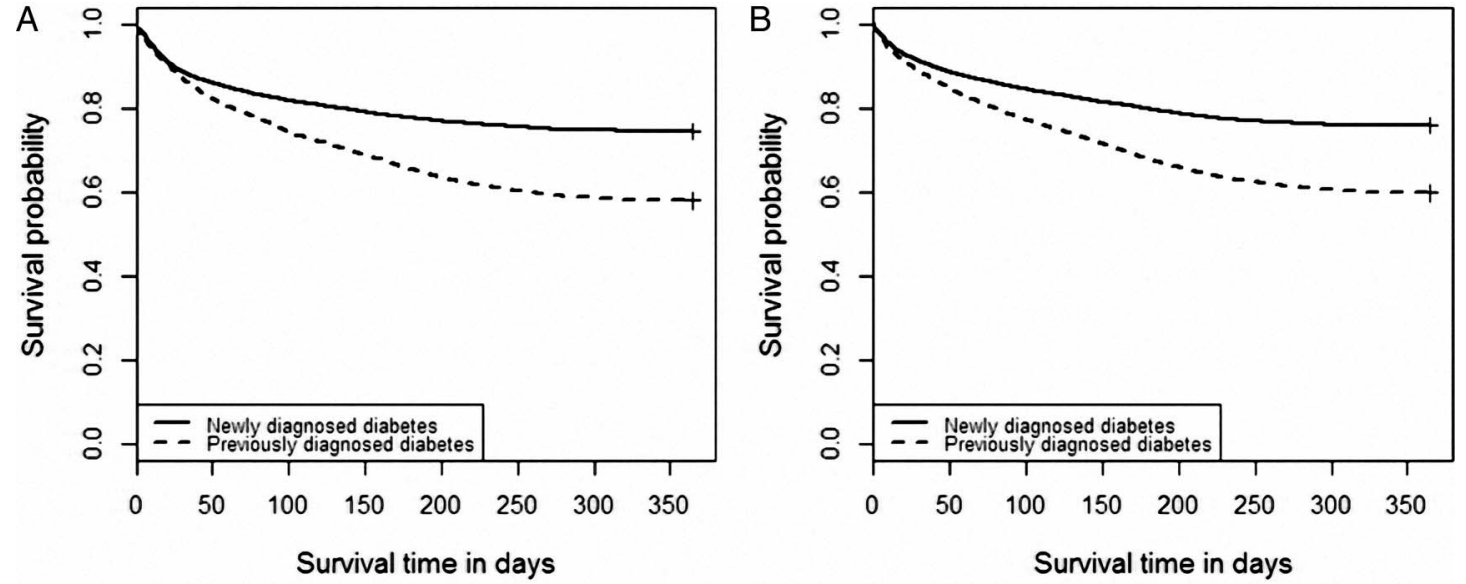

Figure 2 Kaplan-Meier (KM)-survival curves for readmission-free survival (RFS) of patients with (A) type I and (B) type II diabetes by diagnosis status. The 1-year RFS rate of patients with previously diagnosed type I or type II diabetes was significantly lower than that of newly diagnosed patients $(p<0.0001)$.

\section{DISCUSSION}

Our previous study suggested that increased medical costs might partly be driven by the repeated use of hospital resources, ${ }^{25}$ especially for chronic diseases. Therefore, controlling hospital readmission may help to balance the quality of healthcare services and healthcare costs. However, evaluating the profile of hospital readmission has not captured the attention of China's policymakers. This might be because no potential impact factor of readmission has been recorded, evaluated or reported, such as the quality of hospital services and patients' discharge orientations. ${ }^{21}$

In the current study, we uncovered the prevalence of hospital readmission for patients with type I and type II diabetes and objectively assessed the potential impact factors. We have several notable findings: approximately $30 \%$ of patients with diabetic have had multiple hospitalisations, and cerebral infarction (for type I) and diabetes (for type II) were the most frequent reasons for hospital readmission. Consistent with the results of previous studies, ${ }^{26}$ the majority of patients were readmitted within 30 days (including the patients who were readmitted within 7 days), apart from those who were readmitted outside of 90 days after discharge. A prior history of diabetes was an independent risk factor for 1-year RFS and for RFS at any time interval after discharge.

We found that the proportion of readmission for patients with either type I or type II diabetes in China was much higher than in developed countries and also higher than the readmission rates for patients with any disease in developed countries, ${ }^{8} 2627$ which indicates a substantial burden on both patients and the healthcare system in China. Generally, cardiovascular disease (CVD), cerebrovascular diseases (CeVDs), polyneuropathy diseases and some specific cancers, along with hyperglycaemia, were the main causes for patients with diabetes being readmitted to hospitals after the index discharge. Hyperglycaemia is a major risk factor for CVD (including cerebral infarction) and CeVDs, ${ }^{28-31}$ which have become leading causes of death in China, ${ }^{28}$ and the development of complications of diabetes has also been related to glucose levels. ${ }^{32} 33$ Therefore, using hospital-wide interventions to reinforce glycaemic control might be an effective approach to control disease-related readmission. ${ }^{34-36}$ It is unclear why

Table 3 The cumulative readmission-free survival rates between newly and previously diagnosed diabetes within time intervals by type of diabetes

\begin{tabular}{|c|c|c|c|}
\hline Time intervals after discharges & Newly diagnosed diabetes & Previously diagnosed diabetes & p Value \\
\hline \multicolumn{4}{|l|}{ For type I diabetes } \\
\hline 30 days & $0.93(0.93-0.93)$ & $0.92(0.91-0.93)$ & $<0.0001$ \\
\hline 60 days & $0.89(0.88-0.89)$ & $0.87(0.86-0.88)$ & $<0.0001$ \\
\hline 90 days & $0.87(0.86-0.87)$ & $0.83(0.83-0.84)$ & $<0.0001$ \\
\hline 1 year & $0.78(0.78-0.79)$ & $0.67(0.65-0.68)$ & $<0.0001$ \\
\hline \multicolumn{4}{|l|}{ For type II diabetes } \\
\hline 30 days & $0.94(0.94-0.94)$ & $0.93(0.92-0.9)$ & $<0.0001$ \\
\hline 60 days & $0.91(0.91-0.92)$ & $0.89(0.88-0.90)$ & $<0.0001$ \\
\hline 90 days & 0.89 (0.89-0.90) & $0.86(0.85-0.87)$ & $<0.0001$ \\
\hline 1 year & $0.81(0.81-0.82)$ & $0.70(0.69-0.73)$ & $<0.0001$ \\
\hline
\end{tabular}


Figure $3 \mathrm{KM}$-survival curves for readmission-free survival (RFS) of patients with diabetes by predicted risk groups. The predicted in baseline 1-year readmission model from the HRs. Two curves represented low-risk group (upper) and high-risk group (lower) for readmission, respectively, and were well separated, confirming our model has good discrimination. KM-survival curves for RFS as

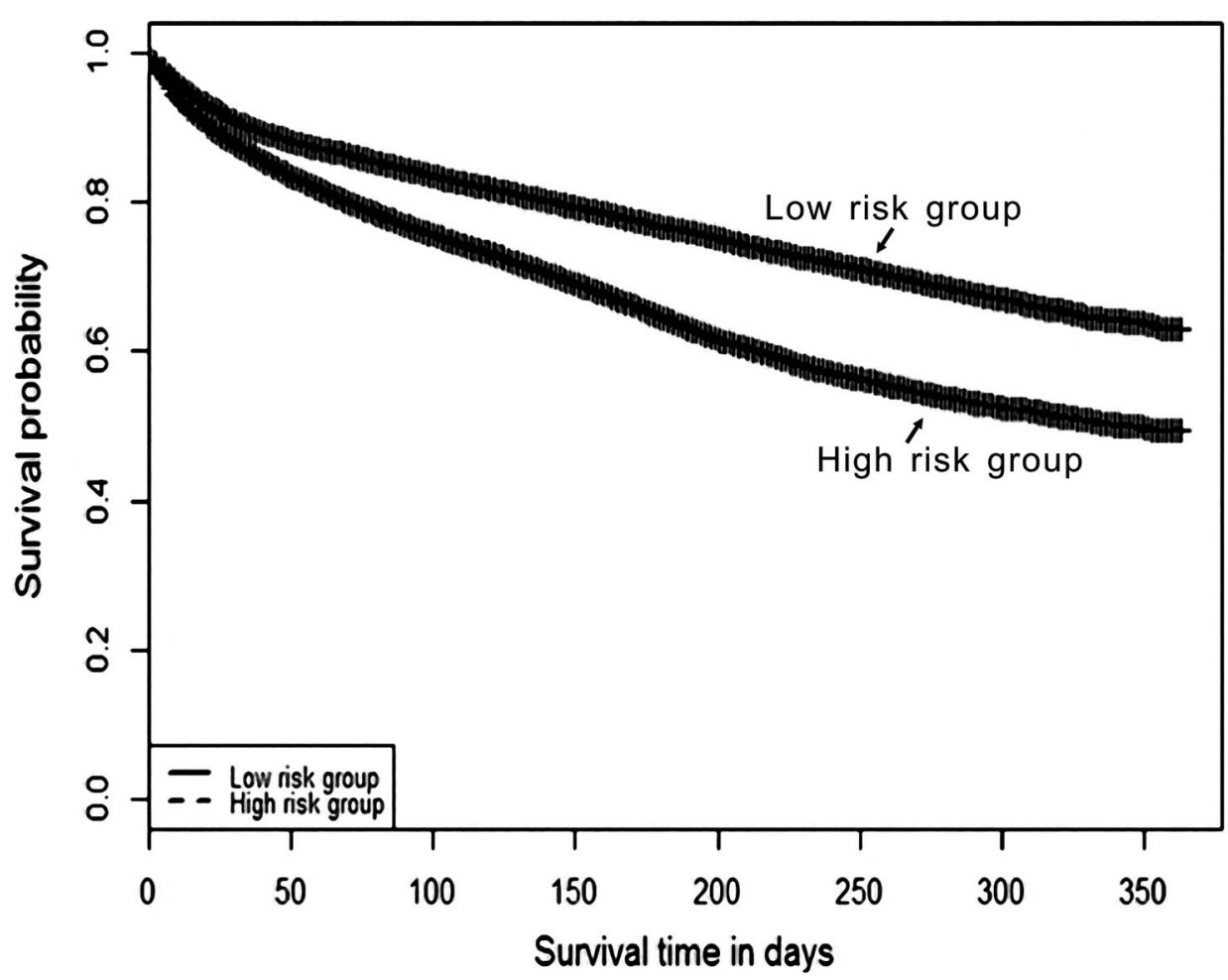

patients discharged with different subtypes of diabetes would have different primary reasons for readmission. For example, the most frequent primary diagnoses were cerebral infarction for patients with type I and type II diabetes. To the best of our knowledge, few studies have compared the differences of disease progression in patients with different subtypes of diabetes, and further investigation of this possibility is warranted. Although the conditions for readmission for patients with a specific subtype of diabetes were relatively consistent at different time intervals, the diagnoses we used relied on the ICD-10 rather than on diagnose-related groups, which might cause difficulty in disease clustering. Thus, we cannot rule out the possibility that some underlying reasons for readmission might not have been discovered.

Finding a suitable time window to implement interventions has continually induced debate $^{37}$; some studies indicated that readmission occurring within a short interval after discharge was affected by the quality of inpatient services and post-discharge follow-ups, whereas readmission at a long interval was explained more by the case mix of the patient. ${ }^{37} 38$ The within 30 days readmission rate has been used by the governments of the USA, Canada, Australia, the UK and New Zealand, to assess the quality of healthcare services. ${ }^{27}{ }^{39-42}$ One of the primary reasons is the large amount of patients readmitted within this interval, which is similar to our result of relatively high rates of readmission being found within 30 days for both types of diabetes. The feasibility of implementing interventions at this interval in China needs to be addressed in the future.

When we considered the cumulative RFS of patients with diabetes for a year, a stable decreased tendency was found. Despite the ongoing interest in understanding readmission internationally, much of the previous work has focused on the differential outcomes between groups, such as the case mix of patients, or on the performance of the healthcare system, ${ }^{14}{ }^{15}{ }_{27}^{43-46}$ without taking diagnosis status into account, which is strongly associated with the prognosis of chronic diseases, especially for patients with diabetes. Cakir et $a l^{t 7}$ found that newly diagnosed patients (the majority of whom might have been previously undiagnosed patients) were more likely to have worse prognosis, which is worthy of attention because a large number of patients in China live with undiscovered diabetes. ${ }^{1}{ }^{48-50}$ We speculated that these undiscovered patients would have flowed into the pool of diagnosed patients and have appeared as 'newly' onset patients after the recent implementation of mass screening for chronic diseases in urban communities of Tianjin. ${ }^{51}$ The screening was launched in 2009 and was motivated by Health System Reform (HSR) in China, which regards controlling the epidemic of chronic disease as a priority. ${ }^{21}$ However, we found that the associations of hazard of readmission with prior history of diabetes were consistent (for 1-year readmission and the readmission at each time interval), suggesting that the history of diabetes is, at least in part, as important as case mix and hospitals' performances in the RFS for patients with diabetes. Our results indicated that a relatively longer duration of diabetes increased the likelihood of poor prognosis and simultaneously suggested that the 'newly diagnosed' patients in Tianjin did not consist of all of the 'previously undiagnosed' patients, and that the screening in Tianjin cannot reveal all undiagnosed patients. 
The factors responsible for readmissions were different at different time intervals, suggesting that the underlying reasons for readmission might also be different at different time intervals between two hospitalisations. We found that the case mix has more impact on the HR of 7-day readmission than on the HR of readmission at other intervals because the comorbidity of $\mathrm{PH}, \mathrm{CHF}$ and ID simultaneously impacted 7-day readmission but not readmission at other intervals. In contrast, no impact of hospital grade was found on 7-day readmission, but there was an impact on 90-day readmission. That is, admission to a secondary or a tertiary hospital at index hospitalisation was a protective factor for RFS at a longer interval. Since high-grade hospitals represent greater ability of providing healthcare in China, we assumed that readmission occurring within 7 days after discharge might be associated more with patient characteristics and that readmissions occurring within a longer interval, perhaps 90 days, might be affected more by the provided healthcare. Further studies are needed to verify our assumption, such as to evaluate the association between the quality of hospital performances and hospital readmission rates.

We found that the comorbidity of $\mathrm{PH}$ acted as a protective factor for RFS within 8-30 days after discharge. Others have examined the role of $\mathrm{PH}$ in determining patient outcomes. For example, for Medicare patients with acute myocardial infarction, $\mathrm{PH}$ played a protective role for within 30 days mortality but a risk role for within 30,60 and 90 days readmission. ${ }^{43}{ }^{52}$ Heart failure patients with $\mathrm{PH}$ have a lower risk for within 30 days readmission. ${ }^{44}$ These results can be explained by factors that are related to the management of chronic diseases. Patients with diabetes with PH might receive closer management, which is effective for reducing the likelihood of short-term prognostic risks. This effect was not observed for within 7 days readmission, due to the complexity of patients' case mixes. This issue should be better understood before interventions are implemented.

Previous studies have proven that patients who were covered by different types of insurances might have different motivations to seek inpatient services, and this is potentially affected by different reimbursement strategies. ${ }^{1653}$ The reimbursement rules of BMI were formulated by considering resident areas (urban or rural), healthcare costs and identities of the beneficiaries (general workers or model workers) as a whole. We found that patients with a $>92 \%$ reimbursement ratio have a higher HR for readmission compared to those with a $90 \%$ reimbursement rate at all intervals after discharge after adjusting for patients' age, employment status, disease conditions and the hospitals' grades. This result suggested that appropriate reimbursement ratios might help to decrease the HR of readmission for patients with diabetes; the latent mechanism for this result will be explored in a future study.

The current study has several limitations. Our baseline variables were disease diagnoses and characteristics of patients and hospitals. However, there may be more elements contributing to readmissions, ${ }^{54}{ }^{55}$ such as socioeconomic status of the patients, that were unavailable for the current study. The data of TBMIRS were limited to patients' information contained in claims, and were updated manually. Despite the integrity of these data, some inaccuracies might exist, such as type I and type II diabetes not being distinguished perfectly. Since we lacked data on the transition of care and outpatient care, we could not assess whether our findings were due to inadequacies in these areas.

\section{CONCLUSION}

Readmission for patients with diabetes was prevalent in Tianjin, China, and the majority of the patients were readmitted outside of 90 days, followed by within 30 days. Cerebral infarction (type I) and diabetes (type II) were the most frequent conditions for readmission at all time intervals after discharge, and a prior history of diabetes was a risk factor for RFS. Readmission within 7 days after discharge might be more associated with patient characteristics, and readmission at a longer interval might be more affected by the quality of the provided healthcare.

Acknowledgements The authors would like to acknowledge the American Journal Experts for their professional editorial assistance.

Contributors XL, YLi and JM carried out the study design, participated in the sequence data collection and drafted the manuscript. YLV and CL participated in the data collection and performed the statistical analysis. JM conceived of the study, and participated in its design, and also coordinated and helped to draft the manuscript.

Funding This work was supported by two National Natural Science Foundations of China grant numbers (71373175) and (81200611).

Competing interests None declared.

Ethics approval The study design and procedures were approved by the Tianjin Labor and Social Security Bureau Institutional Review Board.

Provenance and peer review Not commissioned; externally peer reviewed.

Data sharing statement No addition data are available.

Open Access This is an Open Access article distributed in accordance with the Creative Commons Attribution Non Commercial (CC BY-NC 4.0) license, which permits others to distribute, remix, adapt, build upon this work noncommercially, and license their derivative works on different terms, provided the original work is properly cited and the use is non-commercial. See: http:// creativecommons.org/licenses/by-nc/4.0/

\section{REFERENCES}

1. Yang W, Lu J, Weng J, et al. Prevalence of diabetes among men and women in China. N Engl J Med 2010;362:1090-101.

2. Zhou M, Astell-Burt T, Bi Y, et al. Geographical variation in diabetes prevalence and detection in China: multilevel spatial analysis of 98,058 adults. Diabetes Care 2015;38:72-81.

3. Wang W, McGreevey WP, Fu C, et al. Type 2 diabetes mellitus in China: a preventable economic burden. Am J Manag Care 2009;15:593-601

4. Triomphe A, Flori YA, Costagliola D, et al. The cost of diabetes in France. Health Policy 1988;9:39-48.

5. Ray JA, Valentine WJ, Secnik K, et al. Review of the cost of diabetes complications in Australia, Canada, France, Germany, Italy and Spain. Curr Med Res Opin 2005;21:1617-29. 
6. Domeikiene A, Vaivadaite J, Ivanauskiene R, et al. Direct cost of patients with type 2 diabetes mellitus healthcare and its complications in Lithuania. Medicina (Kaunas) 2014;50: 54-60.

7. Cavassini AC, Lima SA, Calderon IM, et al. Care cost for pregnant and parturient women with diabetes and mild hyperglycemia. Rev Saude Publica 2012;46:334-43.

8. Robbins JM, Webb DA. Diagnosing diabetes and preventing rehospitalizations: the urban diabetes study. Med Care 2006;44:292-6.

9. Liu X, Li C, Gong H, et al. An economic evaluation for prevention of diabetes mellitus in a developing country: a modelling study. BMC Public Health 2013;13:729.

10. Icks A, Claessen H, Kirchberger I, et al. Mortality after first myocardial infarction in diabetic and non-diabetic people between 1985 and 2009. The MONICA/KORA registry. Eur J Epidemiol 2014;29:899-909.

11. Donzé J, Lipsitz S, Bates DW, et al. Causes and patterns of readmissions in patients with common comorbidities: retrospective cohort study. BMJ 2013;347:f7171.

12. Nikolaus T, Specht-Leible N, Kruse W, et al. [The early rehospitalization of elderly patients. Causes and prevention]. Dtsch Med Wochenschr 1992;117:403-7.

13. Oliver D. Readmission rates reflect how well whole health and social care systems function. BMJ 2014;348:g1150.

14. Epstein AM, Jha AK, Orav EJ. The relationship between hospital admission rates and rehospitalizations. $N$ Engl J Med 2011;365:2287-95.

15. Jha AK, Orav EJ, Epstein AM. Public reporting of discharge planning and rates of readmissions. N Engl J Med 2009;361: 2637-45.

16. Schiltz NK, Finkelstein Rosenthal B, Crowley MA, et al. Rehospitalization during the first year of life by insurance status. Clin Pediatr (Phila) 2014:53:845-53.

17. Wang HY, Chew G, Kung CT, et al. The use of Charlson comorbidity index for patients revisiting the emergency department within 72 hours. Chang Gung Med J 2007;30:437-44.

18. Li B, Evans D, Faris $P$, et al. Risk adjustment performance of Charlson and Elixhauser comorbidities in ICD-9 and ICD-10 administrative databases. BMC Health Serv Res 2008;8:12.

19. Southern DA, Quan H, Ghali WA. Comparison of the Elixhauser and Charlson/Deyo methods of comorbidity measurement in administrative data. Med Care 2004;42:355-60.

20. Lum HD, Studenski SA, Degenholtz HB, et al. Early hospital readmission is a predictor of one-year mortality in community-dwelling older Medicare beneficiaries. J Gen Intern Med 2012;27:1467-74.

21. Yip WC, Hsiao WC, Chen W, et al. Early appraisal of China's huge and complex health-care reforms. Lancet 2012;379:833-42.

22. Andersen P, Gill R. Cox's regression model for counting processes, a large sample study. Ann Stat 1982;10:1100-20.

23. Efron B, Tibshirani RJ. An introduction to the bootstrap. New York: Chapman and Hall, 1994.

24. Royston P, Altman DG. External validation of a Cox prognostic model: principles and methods. BMC Med Res Methodol 2013;13:33.

25. Liu XQ, Lin L. The characteristics of rehospitalization in Tianjin China and its influencing factors. Tianjin Medical Insurance 201;13:188-91.

26. Jencks SF, Williams MV, Coleman EA. Rehospitalizations among patients in the Medicare fee-for-service program. $N$ Engl J Med 2009;360:1418-28.

27. Joynt KE, Orav EJ, Jha AK. Thirty-day readmission rates for Medicare beneficiaries by race and site of care. JAMA 2011;305:675-81.

28. He J, Gu D, Wu X. Major causes of death among men and women in China. N Engl J Med 2005;353:1124-34.

29. Chernitsova NS, Kolmykova IA, Kovalenko AV, et al. Prediction of outcome of the acute period of ischemic stroke in young and middle-aged patients. Zh Nevrol Psikhiatr Im S S Korsakova 2014;114:55-9.

30. Mehndiratta MM, Singhal AB, Chaturvedi S, et al. Meeting the challenges of stroke in India. Neurology 2013;80:2246-7.

31. Jimenez-Caballero PE, Lopez-Espuela F, Portilla-Cuenca JC, et al. Detection of vascular risk factors and unknown atrial fibrillation in patients hospitalised in the stroke unit. Rev Neurol 2013:56:464-70.
32. Kim C, Cleary PA, Cowie CC, et al. Effect of glycemic treatment and microvascular complications on menopause in women with type 1 diabetes in the Diabetes Control and Complications Trial/ Epidemiology of Diabetes Interventions and Complications (DCCT/ EDIC) cohort. Diabetes Care 2014;37:701-8.

33. Wukich DK, Armstrong DG, Attinger CE, et al. Inpatient management of diabetic foot disorders: a clinical guide. Diabetes Care 2013;36:2862-71.

34. Dungan KM, Osei K, Nagaraja HN, et al. Relationship between glycemic control and readmission rates in patients hospitalized with congestive heart failure during implementation of hospital-wide initiatives. Endocr Pract 2010;16:945-51.

35. Healy SJ, Black D, Harris C, et al. Inpatient diabetes education is associated with less frequent hospital readmission among patients with poor glycemic control. Diabetes Care 2013;36:2960-7.

36. McAlister FA, Bakal JA, Majumdar SR, et al. Safely and effectively reducing inpatient length of stay: a controlled study of the General Internal Medicine Care Transformation Initiative. BMJ Qual Saf 2014;23:446-56.

37. Joynt KE, Jha AK. Thirty-day readmissions-truth and consequences. N Engl J Med 2012;366:1366-9.

38. Westert GP, Lagoe RJ, Keskimäki I, et al. An international study of hospital readmissions and related utilization in Europe and the USA. Health Policy 2002;61:269-78.

39. Assessment NZHT. Acute medical admissions: a critical appraisal of the literature. Christchurch, Christchurch School of Medicine, 1998.

40. Statistics Canada. Health indicators. Canada: Canadian Institute for Health Information, 2004

41. National Health Ministers' Benchmarking Working Group 1996. First national report on health sector performance indicators: public hospitals-the state of play. Canberra: Australian Institute of Health and Welfare, 1996.

42. Dobrzanska L. Readmissions-an evaluation of reasons for unplanned readmissions of older people: a United Kingdom and international studies literature review. Qual Ageing Older Adults 2004;5:20-8.

43. Aranda JM, Johnson JW, Conti JB. Current trends in heart failure readmission rates: analysis of medicare data. Clin Cardiol 2009;32:47-52

44. Keenan PS, Normand SL, Lin Z, et al. An administrative claims measure suitable for profiling hospital performance on the basis of 30-day all-cause readmission rates among patients with heart failure. Circ Cardiovasc Qual Outcomes 2008;1:29-37.

45. Horsdal HT, Johnsen SP, Søndergaard F, et al. Sulfonylureas and prognosis after myocardial infarction in patients with diabetes: a population-based follow-up study. Diabetes Metab Res Rev 2009;25:515-22.

46. Li Y, Glance LG, Yin J, et al. Racial disparities in rehospitalization among Medicare patients in skilled nursing facilities. Am J Public Health 2011;101:875-82.

47. Cakir M, Altunbas H, Karayalcin U. Hyperglycemia: an independent marker of in-hospital mortality in patients with undiagnosed diabetes. $J$ Clin Endocrinol Metab 2003;88:1402; author reply 1402.

48. Gu D, Reynolds K, Duan X, et al. Prevalence of diabetes and impaired fasting glucose in the Chinese adult population: International Collaborative Study of Cardiovascular Disease in Asia (InterASIA). Diabetologia 2003;46:1190-8.

49. Zuo H, Shi Z, Hussain A. Prevalence, trends and risk factors for the diabetes epidemic in China: a systematic review and meta-analysis. Diabetes Res Clin Pract 2014;1:63-72.

50. Wong KC, Wang Z. Prevalence of type 2 diabetes mellitus of Chinese populations in Mainland China, Hong Kong, and Taiwan. Diabetes Res Clin Pract 2006;73:126-34.

51. Liu XCSLC. The prevalence of chronic disease among residents in Tianjin. Chin J Health Stat 2012;5:667-9.

52. Krumholz HM, Lin Z, Drye EE, et al. An administrative claims measure suitable for profiling hospital performance based on 30-day all-cause readmission rates among patients with acute myocardial infarction. Circ Cardiovasc Qual Outcomes 2011;2:243-52.

53. Mor V, Intrator O, Feng Z, et al. The revolving door of rehospitalization from skilled nursing facilities. Health Aff (Millwood) 2010;29:57-64.

54. Quill TE, Abernethy AP. Generalist plus specialist palliative carecreating a more sustainable model. N Engl J Med 2013;368:1173-5.

55. Lindenauer PK, Lagu T, Rothberg MB, et al. Income inequality and 30 day outcomes after acute myocardial infarction, heart failure, and pneumonia: retrospective cohort study. BMJ 2013;346:f521. 